\title{
OFERTA DA EDUCAÇÃO INFANTIL EM PORTO VELHO NA ZONA RURAL: UMA REALIDADE ESCONDIDA PELOS NÚMEROS OFICIAIS.
}

\author{
Marcelo Lima de Oliveira (Mestrando em Gestão e Desenvolvimento Regional pela \\ Universidade de Taubaté) \\ João Soldi Neves (Professor Doutor da Universidade de Taubaté) \\ Edson Aparecida de Araujo Querido Oliveira (Professor Doutor da Universidade de
}

Taubaté)

\section{RESUMO}

Uma das metas da política pública da educação brasileira é a universalização da educação infantil na pré-escola para as crianças de 04 e 05 anos até o ano de 2016. O estudo tem o objetivo de avaliar o cumprimento desta meta no Município de Porto Velho, tanto na zona urbana como rural, com um pressuposto de que os números oficiais não representam a realidade desta política pública. Os indicadores não conseguem traduzir a realidade da diversidade populacional do Município e para o estudo, foi necessária a utilização dos índices existentes e deles extrair dados mais realistas. Utilizou-se os números do Censo Escolar e os do IBGE para se conseguir ter um cenário mais preciso sobre o percentual de atendimento da educação infantil na zona rural do Município. Os resultados demonstram que existe uma distância muito grande entre os serviços públicos prestados na sede do Município e os oferecidos nos Distritos e, ainda, uma completa ausência da oferta da educação infantil na zona rural.

Palavras chave: Educação. Zona rural. Omissão

\begin{abstract}
Childhood Education Supply in the Rural Areas of Porto Velho: The Reality Hidden by Official Numbers.

One of the goals of the Brazilian educations' policy is to ensure the universal early childhood education in preschool for children between 4 and 5 years of age till 2016. The study intents to evaluate the achievement of this goal in the County of Porto Velho, both in urban and rural areas, with the assumption that the official numbers do not represent the reality of this public policy. The data collected cannot translate the real scenario of the population diversity of the County and to so, it was necessary to use data from previous studies, in order to gather more realistic statistics. To obtain a more precise picture of the attendance percentage in the rural areas of the County, numbers from the School Census and IBGE were used.The results demonstrated that there are still a large gap between the public services provided by the County's headquarters to the districts and also a complete lack of childhood education programs in the rural areas.
\end{abstract}

Key words: Childhood education. Rural zone. Omission 


\section{SEMINÁRIO DE PESQUISA EM CIÊNCIAS HUMANAS - SEPECH \\ Humanidades, Estado e desafios didático-científicos \\ Londrina, 27 a 29 de julho de 2016}

\section{INTRODUÇÃO}

A questão do desenvolvimento, desde a segunda metade do século $\mathrm{XX}$, está deixando de ser uma preocupação apenas da teoria econômica para ser debatida por diversas áreas, como ciências políticas, sociologia e direito. Com isso, as expectativas sobre os legados do desenvolvimento também extrapolam os efeitos econômicos e financeiros.

Nestas novas perspectivas, devem ser analisadas outras variantes além do crescimento econômico, como as responsabilidades ambientais (a relação com a exploração dos recursos naturais) e sociais (a melhoria na qualidade de vida das pessoas).

Sob esta ótica, a educação tem importância ímpar, pois possibilita o crescimento pessoal e o social (BARROS e MEDONÇA, 1997) e é ao mesmo tempo o resultado esperado do desenvolvimento e pressuposto de um novo ciclo (CALEIRO, s.d).

Além da quantidade de anos na escola (escolaridade total), quanto mais tenra for a idade que a pessoa inicie o processo de educação formal, melhor deve ser o aproveitamento no processo de ensino aprendizagem ao longo de sua vida escolar e, em consequência, seus efeitos salutares, já referidos.

Por isso, existe um maior empenho em políticas públicas que possibilitem este acesso antecipado à educação. No Brasil, por exemplo, a idade escolar obrigatória foi reduzida de 07 para 04 anos, para diminuir a diferença entre os que podem custear os estudos de seus filhos no ensino infantil da rede privada e a grande parcela da população que depende da política pública.

O Plano Nacional de Educação tem como um dos seus pilares o atendimento de $100 \%$ da educação infantil até o fim do ano de 2016. Se é certo que a efetivação da pretensão dificilmente ocorrerá, é de se esperar que haverá um atendimento geral perto de $90 \%$. O problema maior é conseguir compreender os fenômenos que dificultam a implementação completa da oferta deste serviço público essencial.

Por outro lado, em razão de sua importância estratégica, os indicadores que pretendem medir o desenvolvimento socialmente sustentável, tem quase que como item obrigatório incluir entre seus objetos de análise a educação, inclusive, o mais conhecido deles o IDH - Índice de desenvolvimento humano.

De toda a forma, com maior ou menor abrangência, todos os indicadores atendem a determinada demanda, em uma vertente generalista, até pela dificuldade de mensurar a diversidade existente na vida real.

Uma destas dificuldades ocorre, por exemplo, na mensuração da política pública educacional no Município de Porto Velho, justamente porque em razão de suas peculiaridades geográficas e possuir uma composição social bastante heterogênea, com parcela da população que habita o núcleo urbano com mais acesso aos serviços públicos até os que residem na zona rural, que estão distantes física e politicamente do poder público.

Estudar a oferta da educação pública infantil, na modalidade pré-escolar, nos diversos segmentos sociais do Município de Porto Velho, passa pela análise dos índices oficiais existentes, a confrontação destes com a realidade demogeográfica e se conseguir um cenário mais preciso do cumprimento da meta desta política pública. Este é o objetivo do presente artigo. 


\section{SEMINÁRIO DE PESQUISA EM CIÊNCIAS HUMANAS - SEPECH \\ Humanidades, Estado e desafios didático-científicos \\ Londrina, 27 a 29 de julho de 2016}

\section{REFERENCIAL TEÓRICO}

Para parte da teoria econômica o crescimento econômico diferencia-se do desenvolvimento econômico, porque naquele a preocupação é muito maior com os resultados materiais, como a economia e o Produto Interno Bruto e o crescimento populacional e, neste, pressupõe um desenvolvimento da própria estrutura social (SACHS, I., 2008).

Sen (2010) vai além e afirma que o desenvolvimento deve contribuir com a própria liberdade das pessoas que compõem a sociedade, com a garantia do aumento da qualidade de vida e de liberdade política e que, para isso, deveriam ser buscados cinco instrumentos para a consecução da liberdade plena: liberdades políticas, facilidades econômicas, oportunidades sociais, garantias de transparência e segurança protetora.

Fundamenta o autor que existem diversas formas de privação da liberdade, como a privação econômica em sentido estrito, a pobreza famélica; a falta de oportunidades sociais, causada pela estratificação social ou impedimentos econômicos; e a falta de liberdade política, que faz com que parte da sociedade não tenha voz nos processos socioeconômicos (SEN, 2010).

Quando não presentes estas liberdades pode haver um descompasso entre a realidade econômica e social, até em países do chamado primeiro mundo pode possuir determinada classe social em nível totalmente destoante de outras, sendo que estas últimas poderiam ter, sozinhas, parâmetros econômicos e sociais menores de países notoriamente mais pobres (SEN, 2010).

Outra das consequências é, por exemplo, a migração (interna ou externa) causada pela necessidade de obtenção de melhores meios de subsistência. A mudança de residência deve existir como opção e não pela falta de opções, como ocorreu no êxodo rural brasileiro ou nos processos migratórios para a Europa atualmente em discussão.

Por conta de tais fatores, contemporaneamente, o desenvolvimento econômico passa a ser um dos componentes do desenvolvimento humano e deve ter por base uma sociedade fundamentada em leis justas e em instituições verdadeiramente comprometidas com o bem-estar político-econômico da coletividade (SOARES JÚNIOR e QUINTELLA, 2008).

Assim, o desenvolvimento recomenda uma estrutura holística, onde devem coexistir uma sociedade socialmente inclusiva e ambientalmente responsável e com desenvolvimento econômico sustentável (SACHS, J., 2015).

O desenvolvimento depende de investimentos, alguns deles materiais, como os realizados na infraestrutura, mas para o desenvolvimento sustentável nos moldes referidos, o mais importante investimento é aquele realizado nas próprias pessoas, especialmente nas crianças (SACHS, J., 2015).

Devem coexistir investimentos em capital físico, aquele relacionado à infraestrutura, mas também no capital humano. Deve ser ressaltado que, do mesmo modo que em relação ao capital físico, em que pode existir o acúmulo individual ou coletivo, pode haver o desenvolvimento do capital humano individual ou de toda a coletividade social (SACHS, J., 2015). Ambos são desejáveis, até porque se busca o progresso social como um todo, mas é certo que para se obter o coletivo, passa-se obrigatoriamente por cada um individualmente. 


\section{SEMINÁRIO DE PESQUISA EM CIÊNCIAS HUMANAS - SEPECH \\ Humanidades, Estado e desafios didático-científicos \\ Londrina, 27 a 29 de julho de 2016}

Um dos princípios basilares do desenvolvimento do capital humano, no aspecto individual, é a cumulatividade, que considera um indivíduo ao longo de toda uma vida, sendo que suas habilidades, saúde e produtividade em qualquer fase do ciclo de vida, dependem das escolhas que são feitas em fases anteriores (SACHS, J., 2015) e aqui cabe o destaque para a educação, que é um processo notadamente cumulativo.

Ainda neste sentido alguns estudos afirmam que o processo cognitivo das crianças começa antes mesmo de seu nascimento, ainda na gravidez e que é essencial, também, o ingresso no ensino formal cada vez mais precoce, com a inclusão na creche (educação infantil), que produzirá efeitos positivos em toda a sua vida estudantil (SACHS, J., 2015).

Em razão disso, o autor americano defende o incremento dos investimentos na fase inicial da vida, que vai do 0(zero) aos 6 (seis) anos, nas áreas da saúde, ambiente seguro e no desenvolvimento cognitivo (educação), pois seria o ciclo crucial para toda a vida da criança (SACHS, J., 2015).

Pode ser afirmado, em razão dos fundamentos expostos, que o investimento já realizado ou em potencial na educação infantil é de suma importância para se verificar o estado de desenvolvimento de uma sociedade e, ainda, avaliar, sua perspectiva de crescimento futuro.

\section{DA DIFICULDADE NA AVALIAÇÃO DO DESENVOLVIMENTO}

Uma das maiores dificuldades em relação ao desenvolvimento econômico, nesta concepção mais ampla, holística, é a sua mensuração, pois se existem diversas variáveis que compõem o que se propôs como desenvolvimento, diversos podem ser os indicadores de avaliação.

Em função disso, diversas são as metodologias, sendo que todas apresentam dois problemas, um relativo à seleção e ponderação das questões relevantes para avaliação e o segundo, em relação à agregação de dados (SIENA, 2008). Sendo que os dois implicam em discricionariedade e com isso um direcionamento daquele que utiliza o indicador.

De toda a forma, é certo que a avaliação do desenvolvimento não pode ser mais realizada com base apenas em aspectos meramente econômicos, sem considerar a qualidade de vida, individual, social e ambiental, abrangendo áreas da saúde, educação, segurança pública, dentre outras (STIGLITZ; SEN e FITOUSSI, 2010).

Os autores (2010) argumentam que se a medição tiver por base conceitos equivocados, por exemplo, for excessivamente econômica, as ações serão direcionadas para isso, sem o comprometimento com o bem-estar de todos. E, até mesmo, a melhoria do próprio bem-estar não pode ser confundida com a melhoria do próprio ser humano.

Mesmo com todos os problemas e entraves, os índices que medem não só os aspectos econômicos foram sendo incorporados, um dos primeiros e mais conhecidos destes é o IDH - Índice do Desenvolvimento Humano adotado pelo PNUD - Programa das Nações Unidas para o Desenvolvimento.

O IDH foi criado por Mahbub ul Haq com a colaboração com Amartya Sen e tem a função de uma medida sintética, do desenvolvimento humano, por não abranger todos os aspectos de desenvolvimento. Conceitos como democracia, participação, 


\section{SEMINÁRIO DE PESQUISA EM CIÊNCIAS HUMANAS - SEPECH \\ Humanidades, Estado e desafios didático-científicos \\ Londrina, 27 a 29 de julho de 2016}

equidade, sustentabilidade são outros dos muitos aspectos do desenvolvimento humano que não são contemplados no IDH (PNUD, 2016).

O IDH utiliza como base três indicadores: saúde, educação e renda, que se traduzem em expectativa de vida; média de anos de educação de adultos e expectativa de anos de escolaridade para as crianças; e, o padrão de vida, expresso em poder de paridade de compra (PNUD, 2016).

Com variações - até pela já mencionada discricionariedade na seleção dos índices - os indicadores de desenvolvimento sustentável utilizam os pilares do IDH, por traduzirem um mínimo do que se pode desejar a uma sociedade e, especificamente em relação à educação, também podem ser considerados os argumentos do autor americano Jeffrey Sachs aqui mencionados.

Um destes exemplos é o impacto da educação infantil nos indicadores, pois o ensino obrigatório só existia a partir do ensino fundamental, aos sete anos de idade. A primeira diferenciação passou a ser com o aumento do ensino fundamental de 08 para 09 anos de duração, a partir dos 06 anos de idade, estabelecido pela Lei 11.114/2005.

A outra alteração normativa impactante foi a Emenda Constitucional n. 59/2009 que alterou o inciso I do artigo 208 da Constituição Federal, para que a educação básica obrigatória fosse dos 04 aos 17 anos, incluindo, portanto, o ensino infantil nesta categoria.

Por fim, no ano de 2014 foi aprovado o Plano Nacional de Educação (Lei 13.005) que tem como Meta I a universalização, até 2016, da educação infantil na préescola para as crianças de 4 (quatro) a 5 (cinco) anos de idade

A reforma atende aos anseios do desenvolvimento sustentável, pois esta é uma das formas de diminuir as diferenças iniciais no processo de ensino aprendizagem, pois as crianças que tem acesso mais cedo à educação formal têm mais facilidade na aprendizagem durante o curso da vida estudantil. E, quase sempre, as que tem este acesso são as das classes mais elevadas, o que ajuda a manter o fosso educacional (WILKISSON; PICKETT, 2010).

Mas é certo que estes três anos a mais na educação básica obrigatória tem reflexos no IDH dos Estados e Municípios, em razão das diferentes etapas do cumprimento das novas previsões legais. E, com isso, impacto nos indicadores de mensuração do desenvolvimento.

Além disso, no caso específico de Porto Velho, existem fatores que influenciam diretamente nos resultados, se a análise for feita com os números obtidos dos indicadores oficiais da oferta da educação infantil.

\section{MÉTODO}

A pesquisa é qualitativa, exploratória e documental. A análise dos dados disponíveis junto ao Instituto Brasileiro de Geografia e Estatística - IBGE, Instituto Nacional de Estudos e Pesquisas Educacionais Anísio Teixeira - INEP e Prefeitura do Município de Porto Velho e será feita sob uma nova perspectiva, com números que devem ser reanalisados, pois a disponibilização destes na forma em que estão publicados não conseguem dimensionar a realidade educacional no Município de Porto Velho, em face da composição geodemográfica diferenciada. 


\section{SEMINÁRIO DE PESQUISA EM CIÊNCIAS HUMANAS - SEPECH \\ Humanidades, Estado e desafios didático-científicos \\ Londrina, 27 a 29 de julho de 2016}

É qualitativa porque haverá um aprofundamento diferenciado e não uma simples análise dos dados já disponibilizados pelas diversas instituições governamentais e que poderá gerar diferentes resultados daqueles já preexistentes.

Exploratória, pois pretende proporcionar maior familiaridade com o problema, com o objetivo de torna-lo mais explícito, para que se compreenda o fenômeno em suas variáveis (KOCHË, 2011).

Assim, serão feitas estimativas com os indicadores populacionais, para se extrair as três dimensões pretendidas, a população urbana, a rural aglomerada e a rural em sentido estrito. Também, por estimativa, será feita a contagem populacional das crianças com 04 e 05 anos, em razão da ausência de dados específicos.

Será analisada somente a educação infantil, na modalidade pré-escola, pois é o obrigatório para o Estado e pais, conforme a previsão constitucional e também porque a meta do Plano Nacional de Educação é de ter a educação infantil, pré-escolar, universalizado até o final do ano de 2016 e, deveria, por conta desta proximidade com o limite temporal, já estar em fase final de implementação.

\section{RESULTADOS E DISCUSSÃO}

\subsection{Contextualização do Município de Porto Velho}

O Município de Porto Velho, capital do Estado de Rondônia, tem área territorial de $34.096 \mathrm{Km} 2$, sendo a maior capital brasileira em extensão territorial, maior até que os Estados de Sergipe e Alagoas (IBGE). Esta grande área faz com que o Município de Porto Velho tenha especificidades que devem ser analisadas quando são feitas comparações com outras capitais de porte assemelhado no aspecto populacional. $\mathrm{O}$ Município de Porto Velho tem em sua administração administrativa 11 distritos, além do núcleo urbano propriamente dito (IBGE, 2016).

Pelo Censo Demográfico de 2010, a população total de Porto Velho era de 428.527 habitantes. Destes, 369.361 residiam na sede administrativa do Município, 21.372 residiam em aglomerados urbanos (Distritos) e mais 37.794 habitantes estavam na Zona Rural

No ano de 2015, conforme previsão do IBGE, a população estimada de Porto Velho era de 502.428 habitantes, o que resulta um aumento demográfico de pouco mais de $17 \%$. Como todos os dados demográficos não estão atualizados, far-se-á, para efeitos do presente estudo, uma aproximação baseada na proporção dos números do Censo de 2010 em comparação com a população estimada oficialmente pelo IBGE, para se chegar um número aproximado da população residente na sede do Município, nos aglomerados populacionais (Distritos) e na Zona Rural.

Com base nestes critérios, serão considerados 433.127 habitantes para a zona urbana, 24.509 para os distritos e 44.345, para a zona rural, para o ano de 2015 .

Em relação à população de 04 e 05 anos, também deverá ser feito uma estimativa estatística, em 2010, conforme os Indicadores Demográficos e Educacionais do MEC, Porto Velho teria 14.404 crianças entre 04 e 05 anos de idade, sendo que destas 13.127 na área urbana e 1.277 na área rural (BRASIL, 2016). 


\section{SEMINÁRIO DE PESQUISA EM CIÊNCIAS HUMANAS - SEPECH \\ Humanidades, Estado e desafios didático-científicos \\ Londrina, 27 a 29 de julho de 2016}

Projetando-se o percentual de crescimento conforme a estimativa populacional de 2015, já referida, seria um número aproximado de 16.852 do total de crianças, sendo 15.358 na área urbana e 1494, na área rural. Da área urbana, pode se extrair o número aproximado das crianças de 04 e 05 anos que vivem em aglomerados urbanos (Distritos) que seria de 834 crianças, com base na proporção da população total. E, com isso, o número estimado de crianças nesta faixa etária no núcleo urbano é de 14.524 , obtido pelo abatimento do número de crianças nos Distritos.

Com tais dados aproximados é que se fará a avaliação do atendimento da educação infantil em cada população e o cumprimento das metas fixadas no Plano Nacional da Educação.

\subsection{Atendimento da pré-escola em Porto Velho}

Os últimos dados oficiais e públicos sobre o atendimento são, respectivamente, de 2015, para o ensino público e do ano de 2014, para as escolas privadas.

No ensino público os dados estão disponíveis no sítio eletrônico do INEP Instituto Nacional de Estudos e Pesquisas Educacionais Anísio Teixeira e referem-se ao Censo Escolar realizado no ano 2015, com a quantidade de alunos matriculados em cada Município.

Em Porto Velho, segundo o Censo escolar, existiam 9.985 alunos na pré-escola, sendo 698 em escolas estaduais urbanas, $8.642 \mathrm{em}$ escolas municipais urbanas e $645 \mathrm{em}$ escolas municipais rurais (INEP, 2016).

A este número podem ser acrescidas as 2.302 crianças atendidas pela rede particular, todas na zona urbana, número este divulgado no Plano Municipal de Educação e que são referentes a outubro de 2014 (PORTO VELHO, 2015).

Quanto às vagas oferecidas na zona rural não foi possível diferenciar se eram referentes aos Distritos ou à zona rural em sentido estrito, ou seja, onde estavam as vagas. Para sanar a dúvida, foi feita visita in loco na sede da Secretaria Municipal da Educação, no mês de janeiro de 2016, a fim de ter acesso aos documentos referentes à localização das referidas vagas.

Isso trouxe dois fatos para o levantamento de dados. $\mathrm{O}$ primeiro é que os números que constam no Censo Educacional são menores que as vagas reais disponibilizadas. Tal discrepância ocorre em razão do já mencionado contínuo aumento de vagas na pré-escola para que seja cumprido o Plano Nacional da Educação e, com isso, são oferecidas novas salas de aula e novas escolas, que são imediatamente ocupadas, independente do final do ano letivo.

Pelo levantamento da Secretaria Municipal de Educação o número total de vagas de Pré-escola, oferecidas pelo sistema municipal de ensino, seria de 731 vagas na Zona Rural e de 10.036 vagas na zona urbana para o ano de 2015.

O segundo fato é que as vagas na Zona Rural se referem somente aos distritos e a zona rural conurbada à zona urbana. Ou seja, bairros ou vilas, que apesar de se manterem interligados por vias e meio de transporte urbanos, estão, para efeitos legais, na zona rural.

Dos 11 distritos, 05 são atendidos com pré-escola, em um total de 538 vagas, sendo que as restantes (193) vagas são localizadas nas áreas conurbadas. Para efeitos do 


\section{SEMINÁRIO DE PESQUISA EM CIÊNCIAS HUMANAS - SEPECH \\ Humanidades, Estado e desafios didático-científicos \\ Londrina, 27 a 29 de julho de 2016}

presente estudo, estas últimas vagas serão computadas para a zona urbana, em razão das características assemelhadas, como a facilidade de acesso às políticas públicas.

$\mathrm{Na}$ zona rural propriamente dita, ou seja, nas residências ou localidades distantes dos aglomerados urbanos (sede do Município ou Distritos) e que vivem basicamente da agropecuária, não existe a oferta da educação infantil.

Com tais variantes, podem ser elaborados dois quadros sobre o atendimento da educação infantil (pré-escola) no Município de Porto Velho, sendo que ambos traduzem, ainda que parcialmente, a realidade desta política pública, mas que não alteraram de modo significativo os resultados da pesquisa.

Atendimento do Ensino Infantil (Pré-escola) da população com idade entre $04 \mathrm{e}$ 05 anos no Município de Porto Velho até dezembro de 2015, incluindo oferta do sistema estadual, municipal e privado.

Pelos números do Censo educacional 2015:

\begin{tabular}{|l|l|l|l|}
\hline Área populacional & $\begin{array}{l}\text { Número de crianças } \\
\text { Estimativa }-2015\end{array}$ & $\begin{array}{l}\text { Número de vagas } \\
2015\end{array}$ & $\begin{array}{l}\text { Percentual } \\
\text { atendimento }\end{array}$ \\
\hline Núcleo urbano & 14.524 & $11.642^{1}$ & $80,15 \%$ \\
\hline Distritos & 834 & 645 & $77,50 \%$ \\
\hline Zona rural & 1494 & $-00-$ & $-00-$ \\
\hline Total & 16.852 & 12.308 & $73,00 \%$ \\
\hline
\end{tabular}

Números atuais informados pela Prefeitura de Porto Velho:

\begin{tabular}{|l|l|l|l|}
\hline Área populacional & $\begin{array}{l}\text { Número de crianças } \\
\text { Estimativa }-2015\end{array}$ & $\begin{array}{l}\text { Número de vagas } \\
2015\end{array}$ & $\begin{array}{l}\text { Percentual de } \\
\text { atendimento }\end{array}$ \\
\hline Núcleo urbano & 14.524 & $12.531^{2}$ & $86,28^{3} \%$ \\
\hline Distritos & 834 & 538 & $64,5 \%$ \\
\hline Zona rural & 1494 & $-00-$ & $-00-$ \\
\hline Total & 16.852 & 13.069 & $77,5 \%$ \\
\hline
\end{tabular}

\section{DISCUSSÃO}

A expectativa inicial era a de que seria constatado que os indicadores socioeconômicos sempre têm suas falhas, por não conseguirem abranger todas as variáveis da realidade fática, e tal fato foi confirmado. Aliás, esta dificuldade quase que impossibilita a análise comparatória das políticas públicas de Porto Velho com as de outras capitais com população assemelhada.

A variação dos percentuais de atendimento vai de $73 \%$ de atendimento até $86 \%$, a depender do critério estabelecido e isso tem, evidentemente, reflexos em índices com o IDH ou outros que levem em consideração a política educacional, em especial, a da pré-escola.

\footnotetext{
${ }^{1}$ Vagas oferecidas pela rede estadual, municipal e privada

${ }^{2}$ Vagas oferecidas pela rede estadual, municipal (urbana e rural conurbada) e privada

${ }^{3} \mathrm{O}$ percentual real é um pouco menor, em razão da população da zona rural conurbada não estar sendo considerada, por falta de estimativa
} 


\section{SEMINÁRIO DE PESQUISA EM CIÊNCIAS HUMANAS - SEPECH \\ Humanidades, Estado e desafios didático-científicos \\ Londrina, 27 a 29 de julho de 2016}

Mas, para além deste descompasso estatístico, os números surgidos são gravíssimos, pois demonstram a manutenção do imenso fosso relativo à política educacional entre a zona urbana e rural.

Utilizando as informações fornecidas pelo Município isso fica bem mais claro, o distanciamento existente entre os que residem na zona metropolitana (por incluir a zona rural conurbada), os que estão nos núcleos urbanos menores (distritos) e a zona rural.

No setor metropolitano existe um horizonte relativamente próximo de cumprir a meta de atendimento de $100 \%$ da educação infantil, na modalidade pré-escola. A mesma situação parece ser a dos 05 distritos onde existem escolas de educação infantil.

Por outro lado, em 06 dos distritos e na zona rural propriamente dita existe uma total ausência da política pública, o que certamente terá um efeito nefasto no futuro, aumentando a distância entre a educação recebida por estas crianças e as que residem nas outras localidades, restringindo o que já mencionado por Amartya Sen, o desenvolvimento como fator de liberdade pessoal.

\section{CONSIDERAÇÕES FINAIS}

A pesquisa foi eficaz ao constatar uma realidade bem diversificada daquela que transparece dos números oficiais do Ministério da Educação sobre o atendimento da educação infantil no Município de Porto Velho.

Era esperado que existisse um descompasso entre a zona urbana e a zona rural, mas não com tanta diferença, com a constatação de uma total ausência da educação infantil na Zona Rural e em mais da metade dos Distritos que compõem a divisão administrativa do Município.

Os resultados demonstram que a política pública educacional, mormente a que se refere a educação infantil, deve ter um olhar diferenciado, não basta ver os números considerando o Município de Porto Velho como uma unidade federativa comum e, sim, como um conjunto de localidades, que possuem, cada uma, suas especificidades.

A implantação da política pública deve ser modificada para atender tamanhas diferenciações. Por exemplo, ainda que exista o problema do transporte escolar rural para a educação infantil, tal fato não impediria a oferta da educação infantil nas demais sedes distritais.

Deve ser feito o alerta aos órgãos de controle sobre a situação apresentada, como nas ações judiciais em tramitação e que tratam da oferta da educação infantil, ou ainda, nas diversas entidades de acompanhamento do Plano Nacional da Educação.

A pesquisa certamente pode servir para diversas ações governamentais ou para novos estudos que visem minorar os efeitos de tamanha distância entre a política pública educacional ofertada na zona urbana e na zona rural.

\section{REFERÊNCIAS}

BRASIL. Constituição Federal (1988). Disponível em $<$ http://www.planalto.gov.br/ccivil_03/Constituicao/Constituicao.htm>. Acesso em 22 jan. 2016. 


\section{SEMINÁRIO DE PESQUISA EM CIÊNCIAS HUMANAS - SEPECH \\ Humanidades, Estado e desafios didático-científicos \\ Londrina, 27 a 29 de julho de 2016}

BRASIL. Lei $\mathbf{n}^{0}$ 9.394, de 20 de dezembro de 1996 (Lei de diretrizes e bases da educação nacional). Disponível em $<$ http://www.planalto.gov.br/ccivil_03/Leis/L9394.htm >. Acesso em 22 jan. 2016.

BRASIL. Lei $\mathbf{n}^{\mathbf{1}} \mathbf{1 1 . 1 1 4}$, de 16 de maio de 2005. Disponível em <http://www.planalto.gov.br/ccivil_03/_Ato2004-2006/2005/Lei/L11114.htm >. Acesso em 22 jan. 2016.

BRASIL, Emenda Constitucional $\mathbf{n}^{0}$ 59, de 11 de novembro de 2009. Disponível em $<$ http://www.planalto.gov.br/ccivil_03/constituicao/emendas/emc/emc59.html $>$. Acesso em 22 jan. 2016.

BRASIL, Lei n. ${ }^{0}$ 13.005, de 25 de junho de 2014 (Plano Nacional da Educação). Disponível em $\quad<\mathrm{http} / /$ www.planalto.gov.br/ccivil_03/_ato20112014/2014/lei/113005.htm>. Acesso em 22 jan. 2016.

BARROS, Ricardo Paes; MEDONÇA, Rosane. Investimento em educação e desenvolvimento econômico. Disponível em $<$ http://www.ipea.gov.br/portal/index.php?option=com_content\&view $=$ article \&id $=3772$ $>$. Acesso em 24 Jan. 2016.

CALEIRO, António. Educação e Desenvolvimento: que tipo de relação existe?. Disponível em $<$ http://www.ela.uevora.pt/download/ELA_ensino_investigacao_cooperacao_04.pdf $>$. Acesso em 24 Jan. 2016.

INSTITUTO BRASILEIRO DE GEOGRAFIA E ESTATÍSTICA - IBGE. Sítio eletrônico disponível em < http://www.ibge.gov.br/home/>. Acesso em 24 jan. 2016.

INSTITUTO NACIONAL DE ESTUDOS E PESQUISAS EDUCACIONAIS ANÍSIO TEIXEIRA - INEP. Censo Escolar. Disponível em <http://portal.inep.gov.br/basicacenso $>$. Acesso em 25 jan. 2016.

KÖCHE, José Carlos. Fundamentos de metodologia científica: teoria da ciência e iniciação à pesquisa. Petrópolis, RJ: Vozes, 2011.

PORTO VELHO. Lei n. 2.228, de 24 de junho de 2015 (Plano Municipal de Educação). Disponível

em $<$ http://www.portovelho.ro.gov.br:81/index.php?option=com_docman\&task=cat_view\& gid $=1383 \&$ Itemid $=662 \&$ limitstart $=45>$. Acesso em 24 jan. 2016 .

PROGRAMA DAS NAÇÕES UNIDAS PARA O DESENVOLVIMENTO - PNUD. O que é IDH. Disponível em <http://www.pnud.org.br/IDH/DH.aspx>.Acesso em 22 jan. 2016.

SACHS, Ignacy. Desenvolvimento: includente, sustentável, sustentado. Rio de Janeiro: Garamond, 2008. 
SACHS, Jeffrey D. The age of sustainable development. NewYork: Columbia University Press, 2015.

SEN, Amartya. Desenvolvimento como liberdade. Tradução de Laura Teixeira Motta, revisão Ricardo Doninelli Mendes. São Paulo: Companhia das Letras, 2010.

SOARES Junior, Jair Sampaio; QUINTELLA, Rogério Hermida. Instrumentalização do Desenvolvimento: teorias, conceitos e indicadores. In Revista Organizações e Sociedade. Salvador: Universidade Federal da Bahia, vol. 1 - n. 45, - abril-junho 2008, p. 61-78.

STIGLIZTZ, Joseph; SEN, Amartya; e, FITOUSSI, Jean-Paul. Mis-measuring our lives: why GDP doesn't add up. New York: The New Press, 2010.

WILKISSON, Richard; PICKETT, Kate. Why greater equality makes societies stronger. New York: Bloomsbury Press, 2010. 